\title{
Influência de propriedades físico-hídricas do solo no crescimento de Pinus taeda
}

\author{
Itamar Antonio Bognola( ${ }^{(1)}$, Renato Antonio Dedecek ${ }^{(2)}$, Osmir José Lavoranti ${ }^{(1)}$, Antonio Rioyei Higa ${ }^{(3)}$
}

\begin{abstract}
(1) Embrapa Florestas, Estrada da Ribeira, Km 111, CP 319, CEP 83411-000, Colombo, PR, iabog@cnpf.embrapa.br, osmir@cnpf.embrapa.br; (2) Pesquisador aposentado da Embrapa Florestas, dedecek@terra.com.br; ${ }^{(3)}$ Universidade Federal do Paraná (UFPR), Departamento de Engenharia Florestal,, Av. Pref. Lothário Meissner, 900, Jardim Botânico, Campus III, CEP 80210-170, Curitiba, PR, higa@ufpr.br
\end{abstract}

\begin{abstract}
Resumo - Foi estudado o rendimento de Pinus taeda L. em função de propriedades físico-hídricas do solo. O trabalho foi baseado em um mapeamento detalhado de solos, na escala 1:10.000, em duas áreas da empresa Battistella Florestal, localizadas nos estados de Santa Catarina e Paraná. Os dados dendrométricos utilizados foram coletados em parcelas de inventário florestal contínuo (PIFCs), em um povoamento com área de 2.252 ha. Foram selecionados 28 PIFC's com árvores de crescimentos diferentes, separadas em dois grupos com idades de 12 e 13/14 anos. Os sítios com árvores de maior idade e de solos com maior teor de argila, em média, apresentaram maior incremento médio anual das árvores. Houve correlações positivas entre o volume de madeira das árvores, a macroporosidade e a porosidade de aeração, nas camadas de solo estudadas, principalmente, nos sítios com árvores de 12 anos de idades. As correlações entre volume de madeira das árvores e microporosidade, umidade atual e disponibilidade de água do solo foram negativas, provavelmente pela menor drenagem dos solos em área sem déficit hídrico. Solos com teores similares de argila e areia apresentaram o maior incremento médio anual das árvores.
\end{abstract}

Termos para indexação: Macroporosidade, porosidade de aeração, textura do solo, volume de madeira.

\section{Influence of soil physical characteristics on growth of Pinus taeda}

\begin{abstract}
The objective of this study was to assess variability of Pinus taeda L. growth in function of the soil physical characteristics. The soils data were obtained from a detailed mapping, in the scale 1:10,000, in two areas of the Forest Company - Battistella Florestal, located in the states of Santa Catarina and Parana. Data on forestry growth was collected from continuous forest inventory, obtained from a population growing on an area of 2,252 ha. On a commercial Pinus taeda plantation 28 plots (CFIP) were selected with trees of different growing rate and they were divided in two similar groups of different ages: 12 and 13/14 years. Sites with older trees and soil with greater clay content showed trees with greater annual mean increment. There was a positive correlation among tree wood volume, soil macroporosity and aeration porosity on both soil depths, mainly for sites with trees of 12 years of age. Correlation among tree wood volume and soil microporosity, actual soil moisture and available soil moisture was negative, probably due to slower soil drainage on an area with no drought periods. Soils with similar contentes of clay and sand were more productive.
\end{abstract}

Index terms: Soil macroporosity, aeration porosity, soil texture, wood volume.

\section{Introdução}

As propriedades físicas do solo são importantes componentes de sua produtividade, uma vez que influenciam a aeração, a capacidade de armazenamento de água e sua disponibilidade para as plantas. Determinam, também, a resistência ao crescimento das raízes (Lacey, 1993).

A umidade do solo é condição essencial para o crescimento das plantas, não só pelo fornecimento de água, mas também pela mobilização e absorção dos nutrientes e pela sua influência na atividade da fauna do solo. Os nutrientes chegam à superfície das raízes por três mecanismos: interceptação, fluxo de massa e difusão. A contribuição da interceptação é pequena, uma vez que as raízes ocupam $1 \%$ do volume de solo, restando como importantes os mecanismos de difusão e fluxo de massa, pois ambos acompanham a movimentação da água do solo causada pela demanda da planta (Morris et al., 2006). 
Um solo com macroporosidade superior à ideal ( $17 \%$ da porosidade total) tem dificuldade em formar fluxo contínuo de água para permitir os mecanismos de movimentação dos nutrientes até a zona radicular das plantas. Por outro lado, solo com dominância de microporosidade ( $>90 \%$ da porosidade total) tem mais poros saturados, facilitando os fluxos de massa e difusão dos nutrientes, mas com menor circulação do ar e com oxigenação deficiente. Desta forma, quando a estrutura do solo não é adequada, pode haver uma redução do crescimento do sistema radicular das plantas, tendo como consequência menor volume de solo a ser explorado pelas raízes, em vista do menor fluxo de ar e água do solo (Wolkowski, 1990).

Segundo Quinteros Doldan (1990), os fatores físicos do solo como a capacidade de retenção de água, a profundidade efetiva do horizonte A e o grau de desenvolvimento do perfil do solo foram os que mais interferiram no crescimento do P. taeda. Snowdon \& Benson (1992) verificaram que o fornecimento de água no solo aumentou o incremento anual em volume de madeira em $P$. radiata e que a adubação isolada favoreceu apenas a biomassa da copa. Correia et al. (1996) também observaram em seus estudos que a disponibilidade de água foi essencial para o crescimento do $P$. taeda. Morris et al. (2006) afirmam que os fatores físicos do solo mais importantes no crescimento das raízes das mudas de P. taeda foram a resistência mecânica, o potencial de água e a aeração do solo. A taxa de crescimento das raízes dependeu do conteúdo de água no solo como um resultado de sua correlação com cada fator.

Dedecek et al. (2008) verificaram para o P. taeda que os maiores teores de água disponível no solo estavam associados a sítios com árvores de maior altura média para serraria e de sítios com árvores com maior DAP entre todos os sítios estudados. Por outro lado, observase, na área de estudo, que havia uma tendência de maior desenvolvimento do $P$. taeda em locais onde os solos eram melhor aerados, não só pela textura mais arenosa superficial, mas pela predominância de frações mais grosseiras subsuperficialmente. Isso motivou o presente estudo que tem o objetivo de avaliar a contribuição dos atributos físicos do solo no crescimento do $P$. taeda.

\section{Material e Métodos}

\section{Área de trabalho}

Os locais de estudos situam-se na porção do Planalto Norte do Estado de Santa Catarina, entre os municípios de Rio Negrinho e Doutor Pedrinho (Figura 1) e outro na região centro-sul do Estado do Paraná (Figura 2). O clima nos dois locais é do tipo Cfa da classificação de Köppen (clima tropical, com verão quente, sem estação seca de inverno, com temperaturas médias do mês mais frio abaixo de $18^{\circ} \mathrm{C}$ e acima de $-3^{\circ} \mathrm{C}$ ). A região caracteriza-se por possuir elevada pluviosidade, chuvas bem distribuídas durante o ano todo e por não ter estação seca definida.

Foi realizado um mapeamento detalhado dos solos, na escala 1:10.000, tendo como classe predominante os CAMBISSOLOS HÚMICOS Alumínicos típicos ou lépticos (Bognola, 2007). Estes solos são medianamente profundos, com altos teores de matéria orgânica (valores superiores a $40 \mathrm{~g} \mathrm{dm}^{-3}$ ) no horizonte superficial (normalmente em torno de $40 \mathrm{~cm}$ a $50 \mathrm{~cm}$ de espessura). São extremamente ácidos e com altos teores de alumínio trocável (valores superiores a 4,0 $\mathrm{cmol}_{\mathrm{c}} \mathrm{dm}^{-3}$ de solo). 


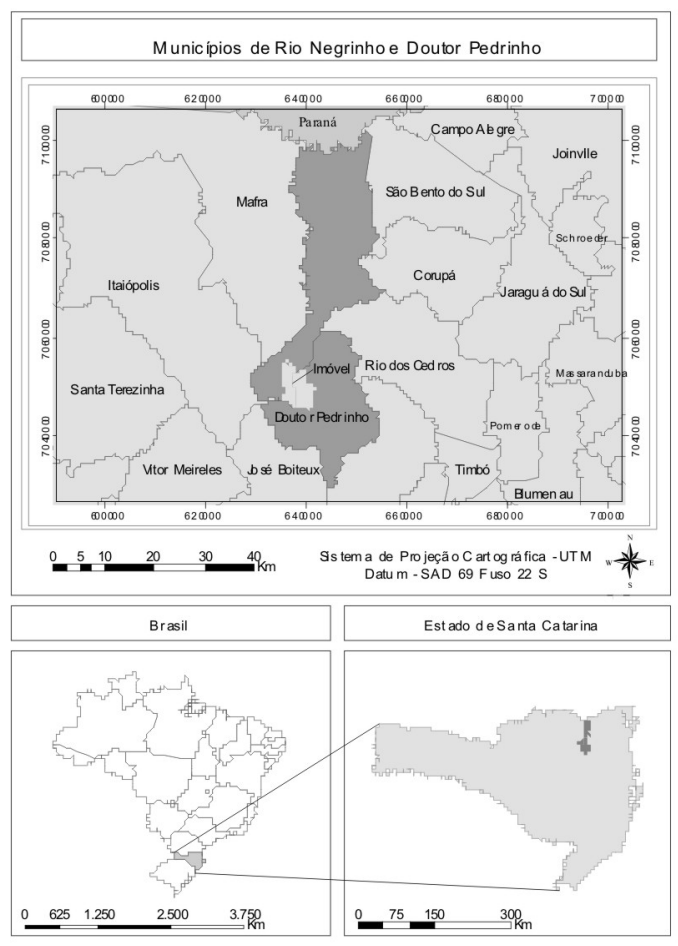

Figura 1. Localização da área piloto 1 no Estado de Santa Catarina. Fonte: IBGE (2006); Battistella Florestal.

A base de dados utilizada neste estudo é proveniente de povoamentos comerciais de $P$. taeda L., coletada em parcelas de inventário florestal contínuo, com área de $500 \mathrm{~m}^{2}$ e espaçamento entre árvores de 2,80 m x 2,80 m.

\section{Amostragens do solo}

Amostras de solo indeformadas foram coletadas com anéis metálicos de $5,8 \mathrm{~cm}$ de diâmetro por $3 \mathrm{~cm}$ de altura nas parcelas de inventário estabelecidas pela Battistella Florestal, nos municípios de Rio Negrinho, SC, e Tijucas do Sul, PR. Foram coletadas três amostras por parcela, a $50 \mathrm{~cm}$ da linha de plantio em duas profundidades: 5 $\mathrm{cm}$ a $10 \mathrm{~cm}$ e $35 \mathrm{~cm}$ a $40 \mathrm{~cm}$. As amostras obtidas foram acondicionadas e levadas para laboratório da Embrapa Florestas para as determinações físico-hídricas, de acordo com metodologia descrita em Claessen (1997).

A porosidade de aeração foi estabelecida como o volume de poros livres de água entre porosidade total e a capacidade de campo. A macroporosidade referese à quantidade de poros maiores que $5 \mathrm{~mm}$, sendo o volume de poros livres de água compreendidos entre a

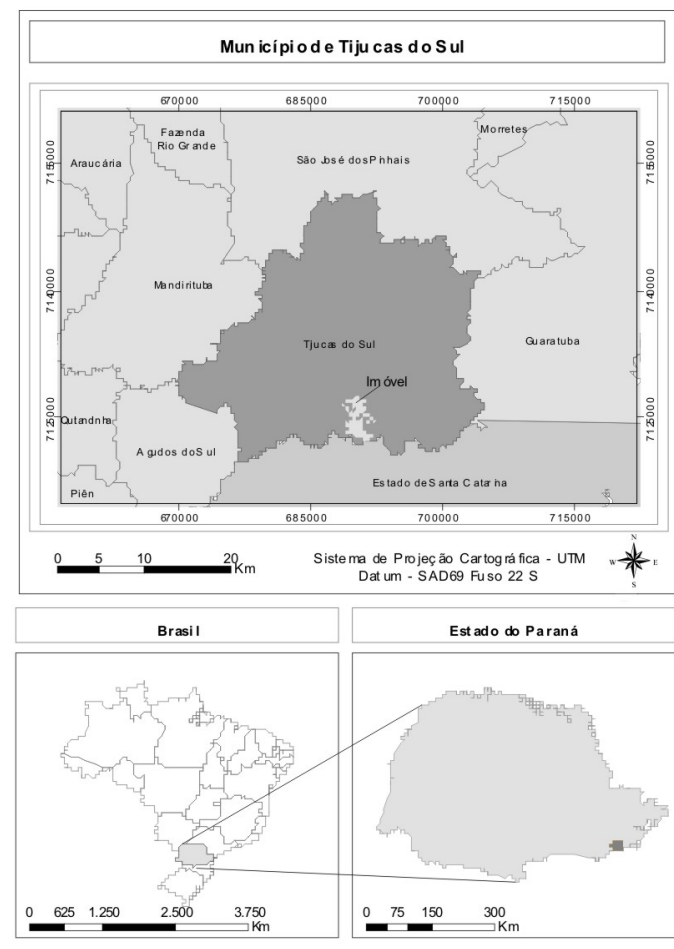

Figura 2. Localização da área piloto 2 no Estado do Paraná. Fonte: IBGE (2006); Battistella Florestal.

porosidade total e a tensão de $6 \mathrm{kPa}$. A água disponível foi estabelecida como o volume de água compreendido entre as tensões de $10 \mathrm{kPa}$ e $1.500 \mathrm{kPa}$.

Os dados de granulometria dos solos das parcelas amostradas estão apresentados na Tabela 1, estando as parcelas classificadas em ordem decrescente, de acordo com a quantidade de areia total. Os teores de argila variaram entre $130 \mathrm{~g} \mathrm{~kg}^{-1}$ e $510 \mathrm{~g} \mathrm{~kg}^{-1}$, nas parcelas com pínus de 12 anos de idade e entre $250 \mathrm{~g} \mathrm{~kg}^{-1}$ e $511 \mathrm{~g}$ $\mathrm{kg}^{-1}$, nas parcelas com pínus de 13/14 anos de idade. Para as características físicas foi aplicada a análise de variância para as médias das parcelas de pínus com 12 anos, separadas das parcelas com 13/14 anos e para as duas profundidades amostradas. A separação das médias destas características foi feita aplicando-se o teste de Tukey a $5 \%$.

Foram realizadas análises de regressão para avaliar as inter-relações entre as características físicas do solo e a influência destas características no crescimento do pínus. 
Tabela 1. Dados de granulometria e matéria orgânica do solo das parcelas com árvores de Pinus taeda de 12 e $13 / 14$ anos de idade, classificados pelo teor de areia, no Município de Rio Negrinho, SC, 2006.

\begin{tabular}{|c|c|c|c|c|c|c|c|c|c|c|}
\hline \multirow[t]{2}{*}{ Município } & \multirow[t]{2}{*}{ Fazenda } & \multirow{2}{*}{$\begin{array}{c}\text { Parcela } \\
\text { (Sítio) }\end{array}$} & Argila & Silte & Areia & $\begin{array}{l}\text { Matéria } \\
\text { ogânica }\end{array}$ & Argila & Silte & Areia & $\begin{array}{l}\text { Matéria } \\
\text { orgânica }\end{array}$ \\
\hline & & & \multicolumn{8}{|c|}{ g. $\mathrm{kg}^{-1}$} \\
\hline & \multicolumn{2}{|c|}{ Profundidade } & \multicolumn{4}{|c|}{$5 \mathrm{~cm} \mathrm{a} 10 \mathrm{~cm}$} & \multicolumn{4}{|c|}{$35 \mathrm{~cm} \mathrm{a} 40 \mathrm{~cm}$} \\
\hline \multicolumn{11}{|c|}{ Idade de 12 anos } \\
\hline & 4 & 2 & 220 & 77 & 703 & 660 & 242 & 72 & 686 & 360 \\
\hline & 3 & 6 & 130 & 200 & 670 & 560 & 169 & 157 & 674 & 400 \\
\hline & 5 & 8 & 308 & 26 & 666 & 790 & 338 & 19 & 643 & 390 \\
\hline & 4 & 23 & 200 & 189 & 611 & 480 & 220 & 20 & 760 & 220 \\
\hline & 4 & 10 & 322 & 94 & 584 & 310 & 373 & 105 & 522 & 260 \\
\hline & 3 & 19 & 229 & 118 & 553 & 550 & 246 & 195 & 559 & 170 \\
\hline & 5 & $6 \mathrm{~b}$ & 360 & 89 & 551 & 480 & 435 & 108 & 457 & 200 \\
\hline & 5 & 5 & 242 & 209 & 549 & 920 & 341 & 258 & 401 & 820 \\
\hline \multirow[t]{7}{*}{ Negrinho } & 3 & 7 & 265 & 183 & 547 & 550 & 323 & 127 & 550 & 190 \\
\hline & 3 & $2 b$ & 336 & 205 & 459 & 770 & 364 & 116 & 520 & 460 \\
\hline & 3 & 11 & 358 & 235 & 407 & 790 & 346 & 42 & 612 & 560 \\
\hline & 4 & 17 & 262 & 367 & 371 & 370 & 362 & 167 & 471 & 30 \\
\hline & 4 & 22 & 510 & 133 & 357 & 680 & 528 & 101 & 371 & 480 \\
\hline & 4 & 20 & 429 & 238 & 333 & 500 & 447 & 243 & 310 & 420 \\
\hline & & média & 300 & 170 & 530 & 600 & 338 & 124 & 538 & 350 \\
\hline \multicolumn{11}{|c|}{ Idade de 13/14 anos } \\
\hline Tijucas & 6 & 5 & 365 & 175 & 460 & 70 & 465 & 150 & 385 & 90 \\
\hline \multirow[b]{2}{*}{ Rio } & 1 & $5 b$ & 250 & 302 & 448 & 650 & 312 & 289 & 601 & 360 \\
\hline & 1 & 7 & 329 & 233 & 438 & 340 & 275 & 193 & 532 & 380 \\
\hline \multirow{2}{*}{ Negrinho } & 1 & 9 & 325 & 254 & 421 & 630 & 334 & 251 & 415 & 420 \\
\hline & 1 & 2 & 306 & 289 & 405 & 410 & 339 & 255 & 406 & 350 \\
\hline \multirow{10}{*}{ Tijucas } & 6 & 4 & 390 & 207 & 403 & 160 & 514 & 159 & 327 & 70 \\
\hline & 6 & $9 b$ & 443 & 154 & 403 & 190 & 458 & 172 & 370 & 90 \\
\hline & 7 & 6 & 419 & 203 & 378 & 100 & 399 & 230 & 371 & 90 \\
\hline & 6 & $7 b$ & 379 & 255 & 366 & 40 & 379 & 278 & 343 & 10 \\
\hline & 7 & $1 b$ & 511 & 181 & 308 & 170 & 543 & 181 & 276 & 80 \\
\hline & 7 & $7 \mathrm{c}$ & 468 & 231 & 301 & 180 & 491 & 236 & 273 & 50 \\
\hline & 6 & 1 & 404 & 318 & 278 & 110 & 432 & 307 & 261 & 110 \\
\hline & 7 & 11 & 540 & 190 & 270 & 220 & 590 & 187 & 223 & 70 \\
\hline & 7 & 10 & 511 & 239 & 250 & 260 & 536 & 236 & 228 & 90 \\
\hline & & média & 403 & 231 & 366 & 250 & 433 & 223 & 358 & 160 \\
\hline
\end{tabular}

\section{Amostragens de Pinus taeda L.}

Constam de medidas de crescimento de $P$. taeda em três idades diferentes (12, 13 e 14 anos), obtidas junto ao Setor de Inventário da Battistella Florestal, em função dos seguintes dados dendrométricos: diâmetro médio à altura do peito (DAPMED); altura média (HMED); altura dominante (HDOM); área basal (G); volume por hectare (VOLHA) e índice médio de incremento anual (IMA) (Tabela 2).
As parcelas foram separadas em dois grupos, de acordo com a idade das árvores de $P$. taeda, 12 e 13/14 anos. A análise de variância dos dados de DAP e altura das árvores mostraram que entre as idades de 13 e 14 anos não havia diferenças significativas, permitindo o agrupamento delas e aumentando o número de sítios para as análises de correlação. 
Tabela 2. Dados de crescimento das árvores de Pínus taeda nas idades de 12 e 13/14 anos, das parcelas selecionadas, classificados em ordem decrescente pelo volume de madeira.

\begin{tabular}{|c|c|c|c|c|c|}
\hline \multirow{2}{*}{ Município } & \multirow{2}{*}{$\begin{array}{c}\text { Parcela } \\
\text { (Sítio) }\end{array}$} & \multirow{2}{*}{$\begin{array}{l}\text { DAP } \\
(\mathrm{cm})\end{array}$} & \multirow{2}{*}{$\begin{array}{c}\text { Altura } \\
\text { (m) }\end{array}$} & Volume & IMA \\
\hline & & & & \multicolumn{2}{|c|}{$\left(\mathrm{m}^{3} \mathrm{ha}^{-1}\right)$} \\
\hline \multicolumn{6}{|c|}{12 anos de idade } \\
\hline \multirow{14}{*}{ Rio Negrinho } & 7 & 19,9 & 14,10 & 428,20 & 35,66 \\
\hline & 6 & 19,7 & 13,75 & 400,65 & 33,36 \\
\hline & 11 & 17,6 & 14,10 & 374,90 & 31,22 \\
\hline & 17 & 21,0 & 16,00 & 370,30 & 30,86 \\
\hline & $2 b$ & 18,8 & 12,95 & 327,15 & 27,24 \\
\hline & 23 & 18,7 & 14,75 & 318,00 & 26,50 \\
\hline & 2 & 16,9 & 13,80 & 298,75 & 24,90 \\
\hline & 19 & 16,6 & 13,10 & 282,05 & 23,49 \\
\hline & 8 & 16,8 & 13,10 & 236,40 & 19,69 \\
\hline & 22 & 15,6 & 12,95 & 227,55 & 18,96 \\
\hline & $6 b$ & 15,2 & 12,00 & 208,20 & 17,34 \\
\hline & 5 & 14,4 & 13,00 & 176,80 & 14,72 \\
\hline & 20 & 13,2 & 11,35 & 168,70 & 14,06 \\
\hline & 10 & 13,4 & 10,70 & 144,40 & 12,03 \\
\hline \multicolumn{6}{|c|}{ 13/14 de idade } \\
\hline \multirow{9}{*}{ Tijucas } & $9 b$ & 23,5 & 20,67 & 573,53 & 38,23 \\
\hline & 6 & 21,6 & 20,22 & 545,60 & 39,00 \\
\hline & 1 & 21,3 & 20,62 & 513,88 & 34,25 \\
\hline & $7 b$ & 21,7 & 21,46 & 508,32 & 33,88 \\
\hline & 5 & 22,5 & 20,53 & 491,05 & 32,73 \\
\hline & $1 b$ & 21,5 & 19,16 & 483,04 & 34,50 \\
\hline & $7 \mathrm{c}$ & 23,8 & 19,34 & 474,92 & 33,90 \\
\hline & 4 & 22,9 & 20,82 & 467,27 & 31,15 \\
\hline & 11 & 20,2 & 16,52 & 389,69 & 27,80 \\
\hline Rio Negrinho & 7 & 21,2 & 15,5 & 389,35 & 30,16 \\
\hline Tijucas & 10 & 21,1 & 18,12 & 387,94 & 27,70 \\
\hline \multirow{3}{*}{ Rio Negrinho } & 2 & 18,5 & 15,14 & 377,21 & 29,02 \\
\hline & 9 & 22,0 & 15,2 & 299,55 & 23,2 \\
\hline & $5 b$ & 20,8 & 14,2 & 272,1 & 21,08 \\
\hline
\end{tabular}

IMA - Incremento médio manual.

\section{Resultados e Discussão}

\section{Pínus com 12 anos de idade}

Nas Tabelas 3 e 4 são apresentadas as médias das características físicas, em que as parcelas estão classificadas de acordo com a produtividade em volume de madeira de Pinus taeda. Para todas as características houve diferença significativa entre os solos das diferentes parcelas amostradas nas duas profundidades. Os dados de macroporosidade apresentados para a profundidade de $5 \mathrm{~cm}$ a $10 \mathrm{~cm}$ (Tabela 3 ) foram substituídos pelas médias de microporosidade na maior profundidade (Tabela 4), pela maior correlação desta característica com os dados de crescimento das árvores. 
Tabela 3. Características físico-hídricas dos solos das parcelas com Pinus taeda com 12 anos de idade, na profundidade de $5 \mathrm{~cm}$ a $10 \mathrm{~cm}$, Rio Negrinho, SC, 2006.

\begin{tabular}{|c|c|c|c|c|c|c|c|}
\hline \multirow{3}{*}{$\begin{array}{c}\text { Parcela } \\
\text { (Sítio) }\end{array}$} & \multirow{3}{*}{$\begin{array}{c}\text { Densidade } \\
\text { do solo } \\
\left(\mathrm{Kg} \mathrm{dm}^{-3}\right)\end{array}$} & \multicolumn{3}{|c|}{ Porosidade } & \multirow{2}{*}{$\begin{array}{l}\text { Umidade } \\
\text { de campo }\end{array}$} & \multirow{2}{*}{$\begin{array}{l}\text { Capac. de } \\
\text { campo }\end{array}$} & \multirow{2}{*}{$\begin{array}{c}\text { Água dispo- } \\
\text { nível }\end{array}$} \\
\hline & & Total & Macro & Aeração & & & \\
\hline & & \multicolumn{6}{|c|}{$\left(\mathrm{cm}^{3} \mathrm{~cm}^{-3}\right)$} \\
\hline 7 & $0,931 \mathrm{e}$ & 0,652 cde & $0,242 \mathrm{abcd}$ & $0,258 \mathrm{abcd}$ & $0,252 \mathrm{hi}$ & $0,394 d$ & $0,121 \mathrm{abc}$ \\
\hline 6 & $0,808 \mathrm{bcd}$ & $0,638 \mathrm{de}$ & $0,321 \mathrm{a}$ & $0,331 \mathrm{a}$ & $0,206 \mathrm{i}$ & $0,307 \mathrm{f}$ & $0,063 \mathrm{~g}$ \\
\hline 11 & $0,701 \mathrm{ab}$ & $0,740 \mathrm{ab}$ & $0,256 \mathrm{abcd}$ & $0,271 \mathrm{abc}$ & $0,367 \mathrm{de}$ & $0,469 \mathrm{~d}$ & $0,128 \mathrm{a}$ \\
\hline 17 & $0,798 \mathrm{bc}$ & $0,714 \mathrm{abc}$ & 0,216 bcde & 0,234 bcde & $0,501 \mathrm{abc}$ & $0,480 \mathrm{~d}$ & 0,077 defg \\
\hline $2 b$ & $0,884 \mathrm{~cd}$ & $0,693 \mathrm{bcd}$ & $0,199 \mathrm{cde}$ & 0,209 cde & $0,321 \mathrm{efg}$ & $0,484 \mathrm{~d}$ & 0,106 abcdef \\
\hline 23 & $0,921 \mathrm{de}$ & $0,699 \mathrm{bcd}$ & $0,292 \mathrm{ab}$ & $0,311 \mathrm{ab}$ & $0,308 \mathrm{fg}$ & $0,389 \mathrm{e}$ & 0,107 abcde \\
\hline 2 & $0,705 \mathrm{ab}$ & $0,700 \mathrm{bcd}$ & $0,282 \mathrm{abc}$ & 0,310 & $0,277 \mathrm{gh}$ & $0,390 \mathrm{e}$ & $0,125 \mathrm{ab}$ \\
\hline 19 & $1,097 \mathrm{f}$ & $0,595 \mathrm{e}$ & $0,183 \mathrm{def}$ & $0,195 \mathrm{cdef}$ & $0,333 \mathrm{ef}$ & $0,399 \mathrm{e}$ & 0,082 bcdefg \\
\hline 8 & $1,020 \mathrm{ef}$ & $0,683 \mathrm{bcd}$ & 0,144 ef & 0,151 ef & $0,530 \mathrm{ab}$ & $0,533 \mathrm{e}$ & $0,042 \mathrm{~g}$ \\
\hline 22 & $0,701 \mathrm{ab}$ & $0,719 \mathrm{ab}$ & $0,243 \mathrm{abcd}$ & $0,250 \mathrm{abcd}$ & $0,451 \mathrm{e}$ & $0,470 \mathrm{~d}$ & $0,069 \mathrm{efg}$ \\
\hline $6 \mathrm{~b}$ & $0,742 \mathrm{ab}$ & $0,746 \mathrm{ab}$ & $0,177 \mathrm{def}$ & $0,183 \mathrm{def}$ & $0,480 \mathrm{bc}$ & $0,563 b c$ & $0,043 \mathrm{~g}$ \\
\hline 5 & $0,653 \mathrm{a}$ & $0,775 \mathrm{a}$ & $0,107 \mathrm{f}$ & $0,112 \mathrm{f}$ & $0,546 \mathrm{a}$ & $0,663 \mathrm{a}$ & $0,057 \mathrm{~g}$ \\
\hline 20 & $0,756 \mathrm{ab}$ & $0,737 \mathrm{ab}$ & 0,142 ef & 0,150 ef & $0,541 \mathrm{ab}$ & $0,587 \mathrm{~b}$ & 0,078 cdefg \\
\hline 10 & 0,987 ef & 0,630 e & 0,210 bcde & 0,225 bcde & $0,389 \mathrm{~d}$ & $0,405 \mathrm{e}$ & 0,118 abcd \\
\hline $\mathrm{CV} \%$ & 8,4 & 5,3 & 5,4 & 22,0 & 8,2 & 5,7 & 28,7 \\
\hline
\end{tabular}

Médias seguidas pela mesma letra não diferem entre si pelo teste de Tukey a 5\%.

Tabela 4. Características físico-hídricas dos solos das parcelas com Pinus taeda com 12 anos de idade, na profundidade de $35 \mathrm{~cm}$ a $40 \mathrm{~cm}$, Rio Negrinho, SC, 2006.

\begin{tabular}{|c|c|c|c|c|c|c|c|}
\hline \multirow{3}{*}{$\begin{array}{c}\text { Parcela } \\
\text { (Sítio) }\end{array}$} & \multirow{3}{*}{$\begin{array}{c}\text { Densidade } \\
\text { do solo } \\
\left(\mathrm{Kg} \mathrm{dm}^{-3}\right)\end{array}$} & \multicolumn{3}{|c|}{ Porosidade } & \multirow{2}{*}{$\begin{array}{l}\text { Umidade de } \\
\text { campo }\end{array}$} & \multirow{2}{*}{$\begin{array}{l}\text { Capacidade } \\
\text { de campo }\end{array}$} & \multirow{2}{*}{$\begin{array}{c}\text { Água } \\
\text { disponível }\end{array}$} \\
\hline & & Total & Micro & Aeração & & & \\
\hline & & \multicolumn{6}{|c|}{$\left(\mathrm{cm}^{3} \mathrm{~cm}^{-3}\right)$} \\
\hline 7 & $1,252 \mathrm{ef}$ & $0,530 \mathrm{gh}$ & $0,353 \mathrm{a}$ & 0,188 cdef & $0,266 \mathrm{~g}$ & $0,342 \mathrm{e}$ & $0,059 \mathrm{bc}$ \\
\hline 6 & $1,177 \mathrm{e}$ & $0,585 \mathrm{defg}$ & $0,371 \mathrm{a}$ & 0,225 abcde & $0,268 \mathrm{~g}$ & $0,360 \mathrm{e}$ & $0,063 \mathrm{abc}$ \\
\hline 11 & $0,847 \mathrm{bc}$ & $0,681 \mathrm{~b}$ & $\begin{array}{l}0,461 \\
\text { cde }\end{array}$ & $0,235 \mathrm{abcd}$ & $0,389 \mathrm{de}$ & $0,445 \mathrm{bc}$ & $0,059 \mathrm{bc}$ \\
\hline 17 & $1,239 \mathrm{ef}$ & $0,549 \mathrm{fgh}$ & $0,449 \mathrm{~cd}$ & $0,098 \mathrm{~g}$ & 0,399 cde & $0,451 \mathrm{bc}$ & $0,046 \mathrm{c}$ \\
\hline $2 b$ & $0,937 \mathrm{~cd}$ & 0,627 bcde & $0,388 \mathrm{a}$ & $0,250 \mathrm{abcd}$ & $0,314 \mathrm{f}$ & $0,377 \mathrm{de}$ & $0,060 \mathrm{bc}$ \\
\hline 23 & $1,360 \mathrm{f}$ & $0,493 \mathrm{~h}$ & $0,387 \mathrm{a}$ & $0,129 \mathrm{fg}$ & $0,366 \mathrm{e}$ & $0,365 \mathrm{e}$ & $0,085 \mathrm{ab}$ \\
\hline 2 & $0,966 \mathrm{~cd}$ & $0,640 \mathrm{bcd}$ & $0,393 \mathrm{ab}$ & $0,277 a b c$ & $0,289 \mathrm{fg}$ & $0,363 \mathrm{e}$ & $0,096 \mathrm{a}$ \\
\hline 19 & $1,220 \mathrm{e}$ & 0,567 efg & $0,439 b c$ & 0,141 efg & $0,408 \mathrm{~cd}$ & $0,426 \mathrm{c}$ & $0,045 \mathrm{c}$ \\
\hline 8 & $0,864 \mathrm{bc}$ & 0,596 cdefg & $0,531 \mathrm{f}$ & $0,089 \mathrm{~g}$ & $0,514 \mathrm{a}$ & $0,507 \mathrm{a}$ & $0,078 \mathrm{ab}$ \\
\hline 22 & $0,880 \mathrm{bc}$ & $0,656 \mathrm{bc}$ & $0,497 \mathrm{def}$ & $0,168 \mathrm{defg}$ & $0,481 \mathrm{ab}$ & $0,488 \mathrm{ab}$ & $0,057 \mathrm{bc}$ \\
\hline $6 \mathrm{~b}$ & $0,772 \mathrm{~b}$ & $0,764 \mathrm{a}$ & $0,398 \mathrm{ab}$ & $0,342 \mathrm{a}$ & $0,373 \mathrm{de}$ & $0,422 \mathrm{~cd}$ & $0,030 \mathrm{c}$ \\
\hline 5 & $0,617 \mathrm{a}$ & $0,781 \mathrm{a}$ & $0,520 \mathrm{f}$ & $0,278 \mathrm{ab}$ & $0,431 \mathrm{c}$ & $0,504 \mathrm{a}$ & $0,064 \mathrm{abc}$ \\
\hline 20 & $1,012 \mathrm{~d}$ & $0,656 \mathrm{bc}$ & $0,541 \mathrm{f}$ & $0,126 \mathrm{fg}$ & $0,478 \mathrm{ab}$ & $0,530 \mathrm{a}$ & $0,073 \mathrm{ab}$ \\
\hline 10 & $1,182 \mathrm{e}$ & $0,601 \mathrm{cdef}$ & 0,498 ef & $0,118 \mathrm{fg}$ & $0,486 \mathrm{ab}$ & $0,483 \mathrm{ab}$ & $0,058 \mathrm{~b} \mathrm{c}$ \\
\hline $\mathrm{CV} \%$ & 4,3 & 3,9 & 3,8 & 16,7 & 3,5 & 3,9 & 19,1 \\
\hline
\end{tabular}

Médias seguidas pela mesma letra não diferem entre si pelo teste de Tukey a 5\%. 
As parcelas mais produtivas ( 7 e 6 ) apresentaram algumas diferenças e semelhanças nas características físico-hídricas (Tabela 3). Elas não diferem entre si nos valores de macroporosidade e porosidade de aeração, mostrando valores elevados característicos de solos com teores de argila entre $250 \mathrm{~g} \mathrm{~kg}^{-1} \mathrm{e} 130 \mathrm{~g} \mathrm{~kg}^{-1}$, perfazendo quase metade da porosidade total destes solos. Por outro lado, apresentaram valores baixos de umidade de campo, mostrando que devem secar mais rápido que muitos dos demais. Os solos destas duas parcelas se diferenciaram significativamente no conteúdo de água disponível, aproximadamente $100 \%$ a menos no solo da parcela 6 em relação ao da parcela 7 . Nos solos das parcelas menos produtivas (10 e 20), com teores de argila entre $300 \mathrm{~g} \mathrm{~kg}^{-1}$ e $400 \mathrm{~g} \mathrm{~kg}^{-1}$, têm-se os menores valores de macroporosidade e porosidade de aeração e os maiores de umidade de campo. Olarieta et al. (2006) relatam que o aumento do conteúdo de areia em solos com $33 \%$ a $51 \%$ de argila, determinou um efeito positivo no crescimento de $P$. radiata, em função do aumento da macroporosidade e porosidade de aeração do solo. Os sítios estudados apresentaram dominância de solos arenosos, em média, com conteúdo de areia de $530 \mathrm{~g} \mathrm{~kg}^{-1}$, variando de $333 \mathrm{~g} \mathrm{~kg}^{-1}$ a $703 \mathrm{~g} \mathrm{~kg}^{-1}$, enquanto o conteúdo de argila foi o maior em apenas um sítio (parcela 22) com $510 \mathrm{~g} \mathrm{~kg}^{-1}$, que ficou no terço inferior em termos de volume de madeira produzida.

Na superfície do solo, os valores de macroporosidade e de porosidade de aeração não foram menores do que $0,10 \mathrm{~cm}^{3} \mathrm{~cm}^{-3}$, tido como limite mínimo para oxigenação adequada do solo. Na camada de $35 \mathrm{~cm}$ a $40 \mathrm{~cm}$, os valores de microporosidade dos solos das parcelas mais e menos produtivas permitem apontar as diferenças. Enquanto as parcelas mais produtivas apresentaram os menores valores de microporosidade, estes foram entre os mais elevados nas parcelas menos produtivas.

Contrastam ainda significativamente os valores de umidade de campo entre os solos destas parcelas, verificando-se os menores nos solos das parcelas mais produtivas e maiores nas menos produtivas. Entre os solos de algumas das parcelas mais produtivas $(11,17$ e 2 b) houve um incremento no conteúdo de areia na camada mais profunda amostrada (Tabela 1), embora, na média, não se verificasse esta diferença de granulometria dos solos. Olarieta et al. (2006) concluíram que a aeração teve influência marcante no crescimento de $P$. radiata.

A influência das características físico-hídricas de macroporosidade, porosidade de aeração e umidade de campo nos volumes de madeira obtidos nas diferentes parcelas pode ser observada na Figura 3.

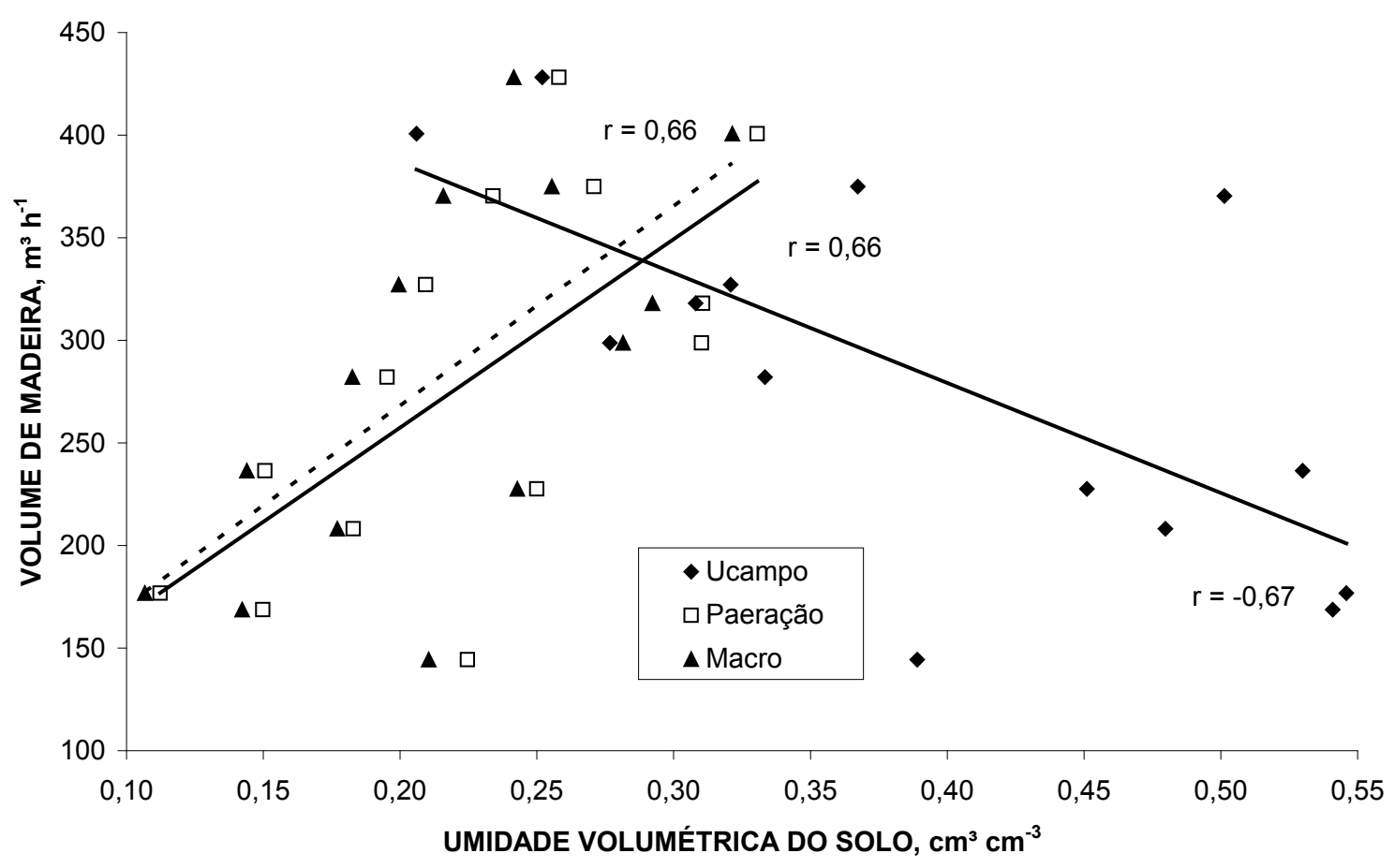

Figura 3. Correlação linear entre volume de madeira de Pinus taeda aos 12 anos e as características físicas do solo - conteúdo de água no momento da coleta (Ucampo), porosidade de aeração (Paeração) e macroporosidade (Macro), na profundidade de $5 \mathrm{~cm}$ a $10 \mathrm{~cm}$, Rio Negrinho, SC, 2006. (n=14). 
As características dos solos de maiores macroporosidades e porosidades de aeração influenciaram positivamente no volume de madeira, mostrando o seu efeito benéfico ao crescimento das árvores. Enquanto a umidade de campo influenciou negativamente com o volume de madeira, mostrando que os solos com drenagens mais lentas, que normalmente são solos com menor macroporosidade, prejudicavam o crescimento das árvores. Olarieta et al. (2006) também comentam que houve uma tendência para solos com menor drenagem apresentarem índices de crescimento de $P$. radiata menores, quando comparados aos solos moderadamente a bem drenados. Deve-se salientar que as parcelas de amostragem que compõem este estudo situam-se em região com chuva bem distribuída durante todo o ano, sem deficiência hídrica, principalmente, nos meses de crescimento (verão). Nesta situação, o excesso de umidade no solo pode causar restrições ao crescimento das árvores.
Quando se considera a camada de $35 \mathrm{~cm}$ a $40 \mathrm{~cm}$, evidencia-se as características negativas ao crescimento das árvores, valores altos de microporosidade, do conteúdo de água na capacidade de campo e do conteúdo de umidade no momento da coleta de solos (Figura 4). Embora as características mais correlacionadas com o volume de madeira tenham sido as negativas nesta profundidade do solo, estes resultados reafirmam o observado na camada de $5 \mathrm{~cm}$ a $10 \mathrm{~cm}$, que o excesso de água no solo prejudicou o desenvolvimento das árvores. Assim, em solos mais bem drenados, com maior macroporosidade e porosidade de aeração e menores microporosidades, houve o maior crescimento das árvores. Alguns solos das parcelas com maior crescimento do $P$. taeda apresentaram incremento do teor de areia (Tabela 1) em relação à camada superficial, o que determina uma menor microporosidade (Tabela 4).

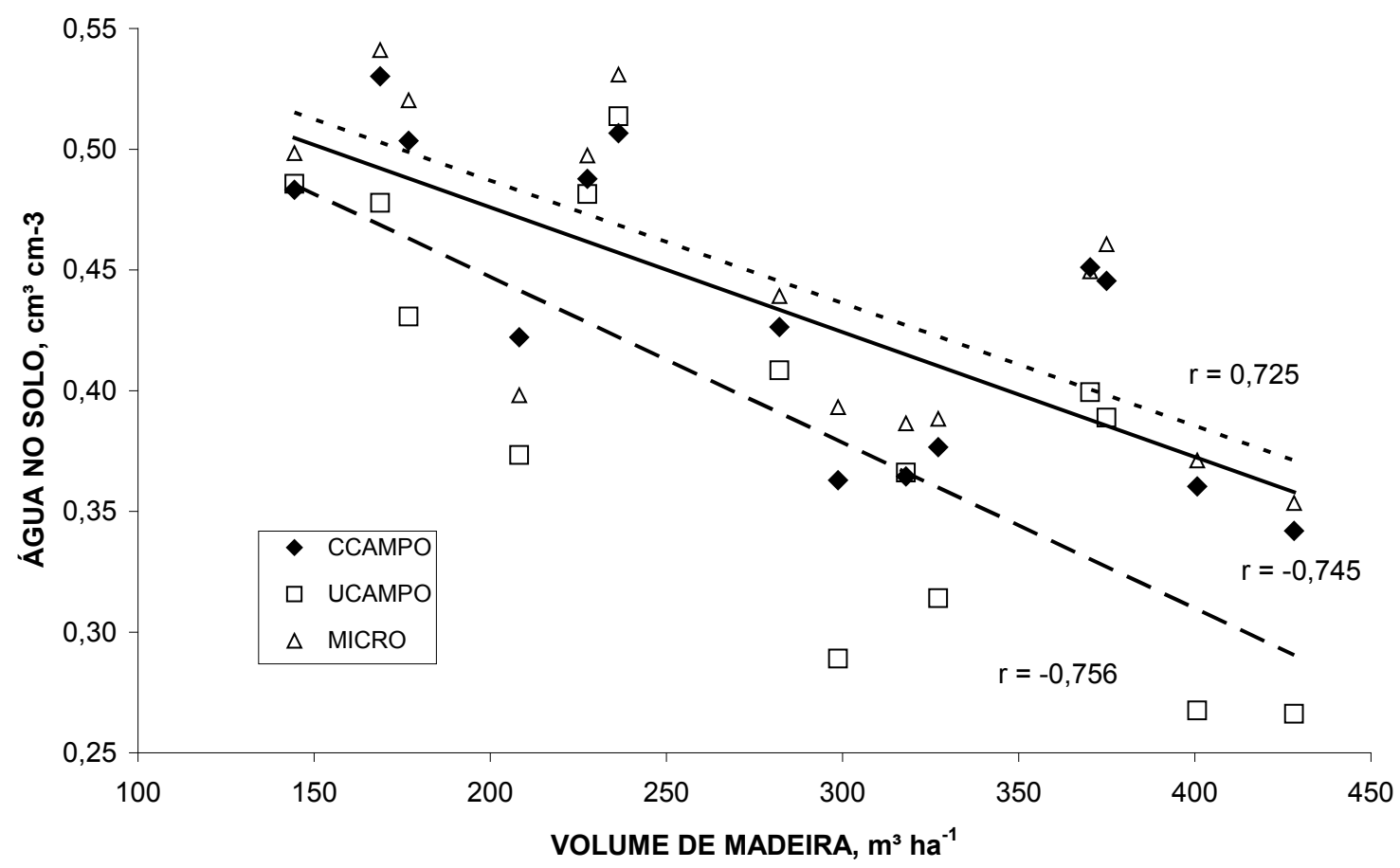

Figura 4. Correlação linear entre volume de madeira de Pinus taeda aos 12 anos e as características físicas do solo - conteúdo de água na capacidade de campo (CCampo), conteúdo de água no momento da coleta (UCampo) e microporosidade (Micro), na profundidade de $35 \mathrm{~cm}$ a $40 \mathrm{~cm}$, Rio Negrinho, SC, 2006 ( $\mathrm{n}=14)$.

Na Figura 5, pode-se observar a alta correlação linear positiva entre as características de conteúdo de água na capacidade de campo e no momento da coleta com a microporosidade da camada de $35 \mathrm{~cm}$ a $40 \mathrm{~cm}$, mostrando que a influência negativa da microporosidade no crescimento das árvores decorre do fato de que o seu incremento leva a um maior teor de água no solo por um período mais longo. Isto inibe a aeração do solo, que se torna mais importante nas camadas mais profundas do solo e também torna mais lenta a drenagem profunda do 
excesso de água, considerando-se que esta região não apresenta déficit de precipitação pluviométrica.

Os valores dos coeficientes de correlação linear (r) entre algumas variáveis físico-hídricas e o volume de madeira não são muito elevados, mas certamente deverão estar em modelos que forem selecionados para explicar o crescimento das árvores. Não se pode esperar que variáveis simples possam explicar quase que totalmente a produtividade observada nas diferentes parcelas que compões este estudo mas, quando consideradas em conjunto, mostram-se coerentes, indicando a importância da aeração do solo em condições de clima sem deficiência hídrica marcante no período de crescimento.

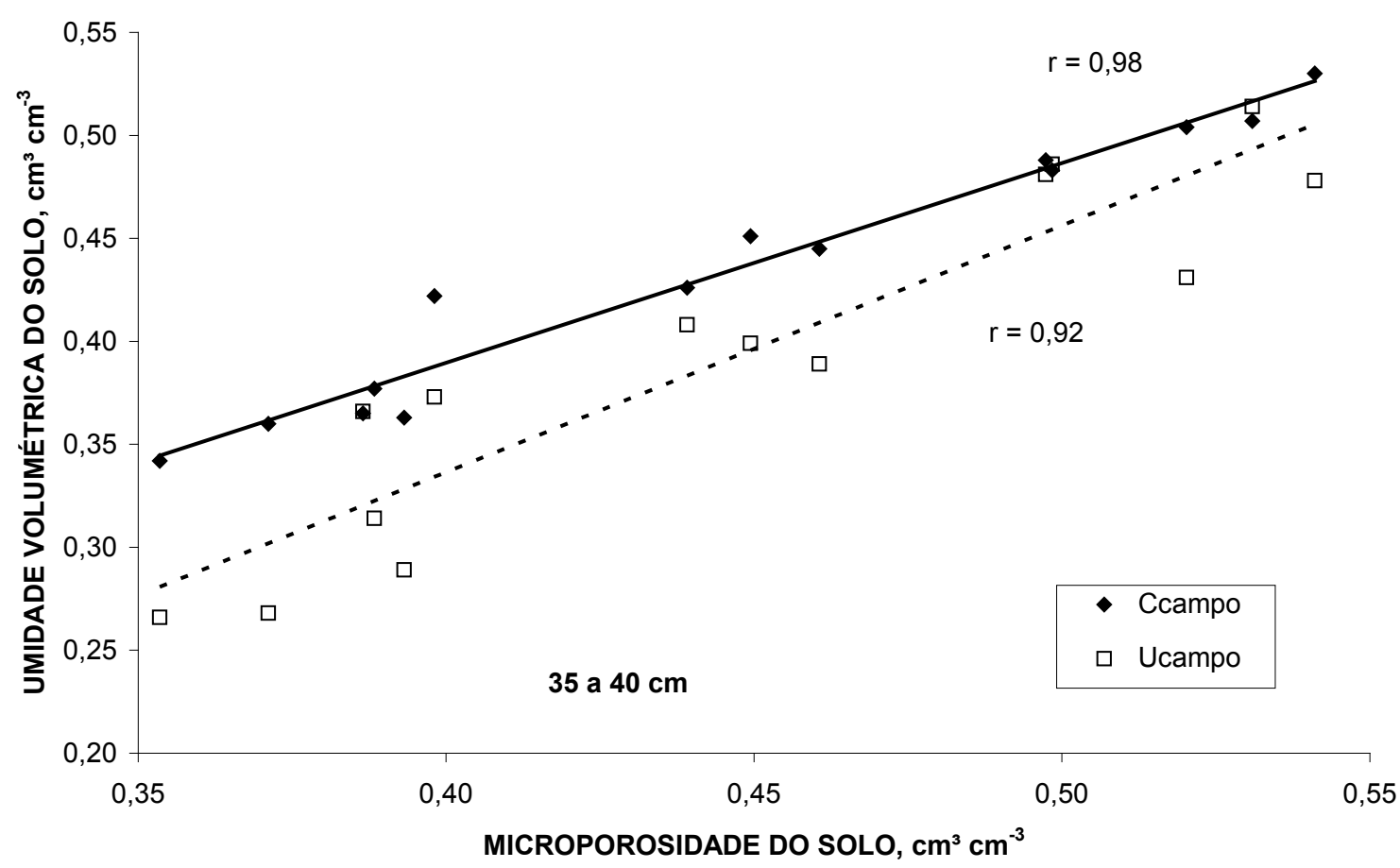

Figura 5. Correlação linear entre as características físicas do solo - conteúdo de unidade na capacidade de campo (Ccampo) e conteúdo de água no momento da coleta (Ucampo) com a microporosidade, na profundidade de $35 \mathrm{~cm}$ a $40 \mathrm{~cm}$, Rio Negrinho, SC, 2006.

\section{Pínus com 13/14 anos de idade}

Os dados das características físico-hídricas para os solos das parcelas com $P$. taeda com idade de 13/14 anos são apresentados nas Tabelas 5 e 6 (profundidades de $5 \mathrm{~cm}$ a $10 \mathrm{~cm}$ e de $35 \mathrm{~cm}$ a $40 \mathrm{~cm}$, respectivamente). Todas as características apresentaram diferenças significativas entre as médias dos solos para cada local e nas duas profundidades amostradas. Não foram observados valores acima dos máximos prejudiciais, de acordo com as texturas de cada solo, para densidade do solo. O solo da parcela $7 \mathrm{c}$ apresentou valores de porosidade de aeração e de macroporosidade abaixo do limite crítico, mas isto não impediu de situar-se entre a metade dos solos com maior crescimento do pínus. Este solo, apesar destes valores, não apresentou densidade elevada e mostrou altos valores de água disponível. A deficiência de aeração pode ser decorrente da granulometria deste solo (Tabela
1), com uma distribuição das três partículas com valores muito semelhantes, o que pode permitir um adensamento natural, com diminuição da porosidade. Este fato pode ter dificultado a drenagem profunda do excesso de água no solo e reduzido os valores da macroporosidade e da porosidade de aeração, considerando-se que estas áreas não apresentam déficit hídrico, principalmente, na estação de crescimento.

Os solos com menores volumes de madeira (parcelas 5 b e 9) apresentam os maiores teores de silte e de areia e, consequentemente, os menores de argila. Os solos mais produtivos (parcelas $9 \mathrm{~b}$ e 6 ) apresentam teores de argila e areia muito próximos, com leve dominância da fração argila. Apesar desta diferença, os valores de macroporosidade, de porosidade de aeração e de umidade atual do solo destas parcelas são muito semelhantes, diferindo apenas no teor de água disponível 
que foi menor nos solos com maior crescimento do pínus. menos produtivos e que conferem uma maior porosidade Pode ter contribuído para esta semelhança os teores de e disponibilidade de água ao solo.

matéria orgânica (Tabela 1), que são maiores nos solos

Tabela 5. Características físico-hídricas dos solos das parcelas com Pinus taeda de 13 a 14 anos de idade, na profundidade de $5 \mathrm{~cm}$ a $10 \mathrm{~cm}$, nos municípios de Rio Negrinho e Tijucas do Sul, SC, 2006.

\begin{tabular}{|c|c|c|c|c|c|c|c|}
\hline \multirow{3}{*}{$\begin{array}{c}\text { Parcela } \\
\text { (Sítio) }\end{array}$} & \multirow{3}{*}{$\begin{array}{c}\text { Densidade } \\
\text { do solo } \\
\left(\mathrm{Kg} \mathrm{dm}^{-3}\right)\end{array}$} & \multicolumn{3}{|c|}{ Porosidade } & \multirow{2}{*}{$\begin{array}{l}\text { Umidade } \\
\text { de campo }\end{array}$} & \multirow{2}{*}{$\begin{array}{c}\text { Capacidade } \\
\text { de campo }\end{array}$} & \multirow{2}{*}{$\begin{array}{c}\text { Água } \\
\text { disponível }\end{array}$} \\
\hline & & Total & Macro & Aeração & & & \\
\hline & & \multicolumn{6}{|c|}{$\left(\mathrm{cm}^{3} \mathrm{~cm}^{-3}\right)$} \\
\hline $9 b$ & 0,909 cdef & 0,670 bcde & $0,340 \mathrm{a}$ & $0,291 \mathrm{abcd}$ & 0,308 ef & $0,379 \mathrm{fg}$ & $0,047 \mathrm{i}$ \\
\hline 6 & $0,510 \mathrm{a}$ & $0,736 \mathrm{a}$ & 0,281 abcde & $0,290 \mathrm{abcd}$ & $0,387 \mathrm{~cd}$ & 0,446 cde & $0,062 \mathrm{efg}$ \\
\hline 1 & $0,965 \mathrm{efg}$ & $0,628 \mathrm{def}$ & $0,215 \mathrm{de}$ & $0,220 \mathrm{de}$ & 0,372 cde & 0,409 defg & $0,060 \mathrm{fgh}$ \\
\hline $7 b$ & $1,103 \mathrm{~g}$ & 0,612 ef & 0,252 bcde & 0,226 cde & 0,304 ef & 0,386 efg & $0,046 \mathrm{i}$ \\
\hline 5 & $0,951 \mathrm{efg}$ & $0,685 \mathrm{abcd}$ & $0,336 \mathrm{a}$ & 0,282 abcde & $0,389 \mathrm{~cd}$ & 0,403 defg & 0,055 ghi \\
\hline $1 b$ & 0,993 efg & $0,646 \mathrm{cdef}$ & $0,122 \mathrm{f}$ & $0,125 \mathrm{f}$ & $0,504 \mathrm{ab}$ & $0,521 \mathrm{ab}$ & $0,049 \mathrm{hi}$ \\
\hline $7 \mathrm{c}$ & $1,043 \mathrm{efg}$ & $0,631 \mathrm{def}$ & $0,051 \mathrm{f}$ & $0,074 \mathrm{f}$ & $0,546 \mathrm{a}$ & $0,558 \mathrm{a}$ & 0,070 ef \\
\hline 4 & $1,070 \mathrm{fg}$ & $0,595 \mathrm{f}$ & $0,223 \mathrm{cde}$ & $0,228 \mathrm{cde}$ & $0,360 \mathrm{de}$ & $0,367 \mathrm{fg}$ & $0,050 \mathrm{hi}$ \\
\hline 11 & $0,779 \mathrm{bcd}$ & $0,695 \mathrm{abc}$ & $0,205 \mathrm{e}$ & $0,211 \mathrm{e}$ & $0,477 \mathrm{ab}$ & $0,484 \mathrm{bc}$ & $0,072 \mathrm{de}$ \\
\hline 7 & 0,896 bcde & $0,703 \mathrm{abc}$ & $0,311 \mathrm{ab}$ & $0,332 \mathrm{a}$ & $0,301 \mathrm{ef}$ & $0,371 \mathrm{fg}$ & $0,084 \mathrm{c}$ \\
\hline 10 & $0,913 \mathrm{def}$ & $0,706 \mathrm{abc}$ & 0,236 bcde & 0,241 bcde & $0,442 \mathrm{bc}$ & $0,465 \mathrm{bcd}$ & 0,052 ghi \\
\hline 2 & $0,767 \mathrm{bcd}$ & $0,691 \mathrm{abcd}$ & $0,291 \mathrm{abc}$ & $0,307 \mathrm{ab}$ & $0,263 \mathrm{f}$ & 0,384 efg & $0,082 \mathrm{~cd}$ \\
\hline 9 & $0,736 \mathrm{~b}$ & $0,723 \mathrm{ab}$ & $0,285 \mathrm{abcd}$ & $0,299 a b c$ & $0,348 \mathrm{de}$ & 0,424 cdef & $0,110 \mathrm{a}$ \\
\hline $5 \mathrm{~b}$ & $0,750 \mathrm{bc}$ & 0,654 cdef & $0,291 \mathrm{abc}$ & $0,306 \mathrm{ab}$ & 0,304 ef & $0,348 \mathrm{~g}$ & $0,097 \mathrm{~b}$ \\
\hline $\mathrm{CV} \%$ & 10,7 & 5,5 & 18,3 & 17,9 & 11,4 & 9,1 & 9,8 \\
\hline
\end{tabular}

Médias seguidas pela mesma letra não diferem entre si pelo teste de Tukey a $5 \%$.

Tabela 6. Características físico-hídricas dos solos das parcelas com Pinus taeda de 13 a 14 anos de idade, na profundidade de $35 \mathrm{~cm}$ a $40 \mathrm{~cm}$, nos municípios de Rio Negrinho e Tijucas do Sul, SC, 2006.

\begin{tabular}{|c|c|c|c|c|c|c|c|}
\hline \multirow{3}{*}{$\begin{array}{l}\text { Parcela } \\
\text { (Sítio) }\end{array}$} & \multirow{3}{*}{$\begin{array}{c}\text { Densidade } \\
\text { do solo } \\
\left(\mathrm{Kg} \mathrm{dm}^{-3}\right)\end{array}$} & \multicolumn{3}{|c|}{ Porosidade } & \multirow{2}{*}{$\begin{array}{l}\text { Umidade } \\
\text { de campo }\end{array}$} & \multirow{2}{*}{$\begin{array}{l}\text { Capacidade } \\
\text { de campo }\end{array}$} & \multirow{2}{*}{$\begin{array}{c}\text { Água } \\
\text { disponível }\end{array}$} \\
\hline & & Total & Macro & Aeração & & & \\
\hline & & \multicolumn{6}{|c|}{$\left(\mathrm{cm}^{3} \mathrm{~cm}^{-3}\right)$} \\
\hline $9 b$ & $1,359 \mathrm{~d}$ & $0,528 \mathrm{e}$ & $0,134 \mathrm{~cd}$ & $0,121 \mathrm{~cd}$ & $0,363 \mathrm{bcd}$ & 0,407 defg & $0,024 \mathrm{e}$ \\
\hline 6 & $1,192 \mathrm{c}$ & 0,603 abcd & $0,143 \mathrm{~cd}$ & $0,108 \mathrm{~d}$ & $0,403 \mathrm{abc}$ & $0,495 \mathrm{abc}$ & 0,052 bcde \\
\hline 1 & $1,114 \mathrm{bc}$ & 0,570 bcde & $0,111 \mathrm{~cd}$ & $0,113 \mathrm{~d}$ & $0,435 \mathrm{ab}$ & $0,457 \mathrm{bcd}$ & $0,038 \mathrm{de}$ \\
\hline $7 b$ & $1,135 \mathrm{bc}$ & $0,537 \mathrm{de}$ & $0,165 \mathrm{bcd}$ & $0,169 \mathrm{bcd}$ & $0,365 \mathrm{bcd}$ & $0,368 \mathrm{~g}$ & 0,040 cde \\
\hline 5 & $1,035 \mathrm{ab}$ & $0,617 \mathrm{ab}$ & $0,286 \mathrm{a}$ & $0,256 \mathrm{a}$ & $0,389 \mathrm{abcd}$ & $0,361 \mathrm{~g}$ & 0,051 bcde \\
\hline $1 b$ & $1,095 \mathrm{abc}$ & $0,606 \mathrm{abc}$ & $0,156 \mathrm{bcd}$ & $0,160 \mathrm{~cd}$ & $0,449 \mathrm{ab}$ & $0,446 \mathrm{~cd}$ & $0,036 \mathrm{de}$ \\
\hline $7 \mathrm{c}$ & $1,028 \mathrm{ab}$ & $0,623 \mathrm{ab}$ & $0,108 \mathrm{~cd}$ & $0,113 \mathrm{~d}$ & $0,511 \mathrm{a}$ & $0,510 \mathrm{a}$ & $0,073 \mathrm{ab}$ \\
\hline 4 & $1,019 \mathrm{ab}$ & $0,619 \mathrm{ab}$ & $0,118 \mathrm{~cd}$ & $0,120 \mathrm{~cd}$ & $0,481 \mathrm{ab}$ & $0,498 \mathrm{ab}$ & $0,053 \mathrm{bcd}$ \\
\hline 11 & $1,104 \mathrm{bc}$ & 0,546 cde & $0,096 \mathrm{~d}$ & $0,099 \mathrm{~d}$ & $0,443 \mathrm{ab}$ & $0,447 \mathrm{bcd}$ & 0,044 cde \\
\hline 7 & $1,017 \mathrm{ab}$ & $0,631 \mathrm{ab}$ & $0,185 \mathrm{bc}$ & $0,205 \mathrm{abc}$ & $0,370 \mathrm{bcd}$ & $0,426 \mathrm{def}$ & $0,067 \mathrm{abc}$ \\
\hline 10 & $1,058 \mathrm{abc}$ & 0,565 bcde & $0,120 \mathrm{~cd}$ & $0,125 \mathrm{~cd}$ & $0,423 \mathrm{abc}$ & $0,440 \mathrm{de}$ & $0,053 \mathrm{bcd}$ \\
\hline 2 & $1,082 \mathrm{abc}$ & 0,568 bcde & $0,169 \mathrm{bcd}$ & $0,180 \mathrm{abcd}$ & $0,276 \mathrm{~d}$ & $0,388 \mathrm{fg}$ & $0,075 \mathrm{ab}$ \\
\hline 9 & 0,948 a & $0,644 \mathrm{a}$ & $0,231 \mathrm{ab}$ & $0,252 \mathrm{ab}$ & $0,308 \mathrm{~cd}$ & $0,392 \mathrm{efg}$ & $0,086 \mathrm{a}$ \\
\hline $5 b$ & $1,081 \mathrm{abc}$ & 0,583 abcde & $0,140 \mathrm{~cd}$ & $0,152 \mathrm{~cd}$ & $0,377 \mathrm{bcd}$ & 0,431 def & $0,091 \mathrm{a}$ \\
\hline $\mathrm{CV} \%$ & 4,9 & 4,0 & 18,8 & 19,5 & 11,0 & 4,2 & 17,9 \\
\hline
\end{tabular}

Médias seguidas pela mesma letra não diferem entre si pelo teste de Tukey a $5 \%$. 
A dominância da fração argila pode ter contribuído para um maior incremento médio anual, observado nos sítios com árvores de 13/14 anos (Tabela 1), comparando-se aos sítios com árvores de 12 anos. $\mathrm{O}$ incremento médio anual máximo nos sítios com árvores de 13/14 anos foi de $39 \mathrm{~m}^{3} \mathrm{ha}^{-1}$ ano $^{-1}$, enquanto nos sítios com árvores de 12 anos foi de $35,7 \mathrm{~m}^{3} \mathrm{ha}^{-1} \mathrm{ano}^{-1}$. Rigatto et al. (2004) também relatam o maior crescimento de P. taeda em solos com dominância da fração argila, como sendo a variável mais importante para os sítios estudados. Chamam também a atenção os teores de matéria orgânica destes solos (Tabela 1) em relação aos solos dos sítios com árvores de 12 anos de idade, chegando a ser em média nestes últimos maior que o dobro na camada de $5 \mathrm{~cm}$ a $10 \mathrm{~cm}$. As parcelas mais produtivas na idade de 13/14 anos (9b e 6) apresentaram teores de matéria orgânica (Tabela 1) menores que a média dos solos dos sítios estudados nesta idade.

$\mathrm{Na}$ camada de $35 \mathrm{~cm}$ a $40 \mathrm{~cm}$, o solo da parcela 11 apresentou valores de macroporosidade e porosidade de aeração menores que o limite e outros solos também mostraram valores muito próximos do limite mínimo. Trata-se do solo com maior conteúdo de argila entre os que fizeram parte deste estudo $\left(590 \mathrm{~g} \mathrm{~kg}^{-1}\right)$. Em ambas as camadas, os solos das parcelas com maior crescimento de pínus apresentaram os menores valores de conteúdo de água disponível para as plantas, exatamente o oposto dos solos das parcelas menos produtivas. As diferenças de conteúdo de argila e areia total entre os solos das parcelas deste grupo são menores do que as apresentadas nas parcelas com pínus de 12 anos, variando o teor de argila de $275 \mathrm{~g} \mathrm{~kg}^{-1}$ a $590 \mathrm{~g} \mathrm{~kg}^{-1}$ e o de areia total entre $223 \mathrm{~g} \mathrm{~kg}^{-1}$ e $601 \mathrm{~g} \mathrm{~kg}^{-1}$.

As correlações lineares mais expressivas entre o volume de madeira produzido e as características físico-hídricas dos solos das parcelas amostradas foram com o conteúdo de água disponível (Figura 6). Estas correlações, para ambas as profundidades, foram negativas, mostrando que um aumento do conteúdo de água disponível diminuiu o crescimento do pínus. $\mathrm{O}$ que pode parecer um contra-senso, as plantas não serem beneficiadas pelo maior volume de água disponível, vem confirmar os resultados obtidos com o pínus de 12 anos. Para aquelas parcelas, o aumento da microporosidade reduziu o crescimento das árvores, o que normalmente está associado com o maior conteúdo de argila nos solos.

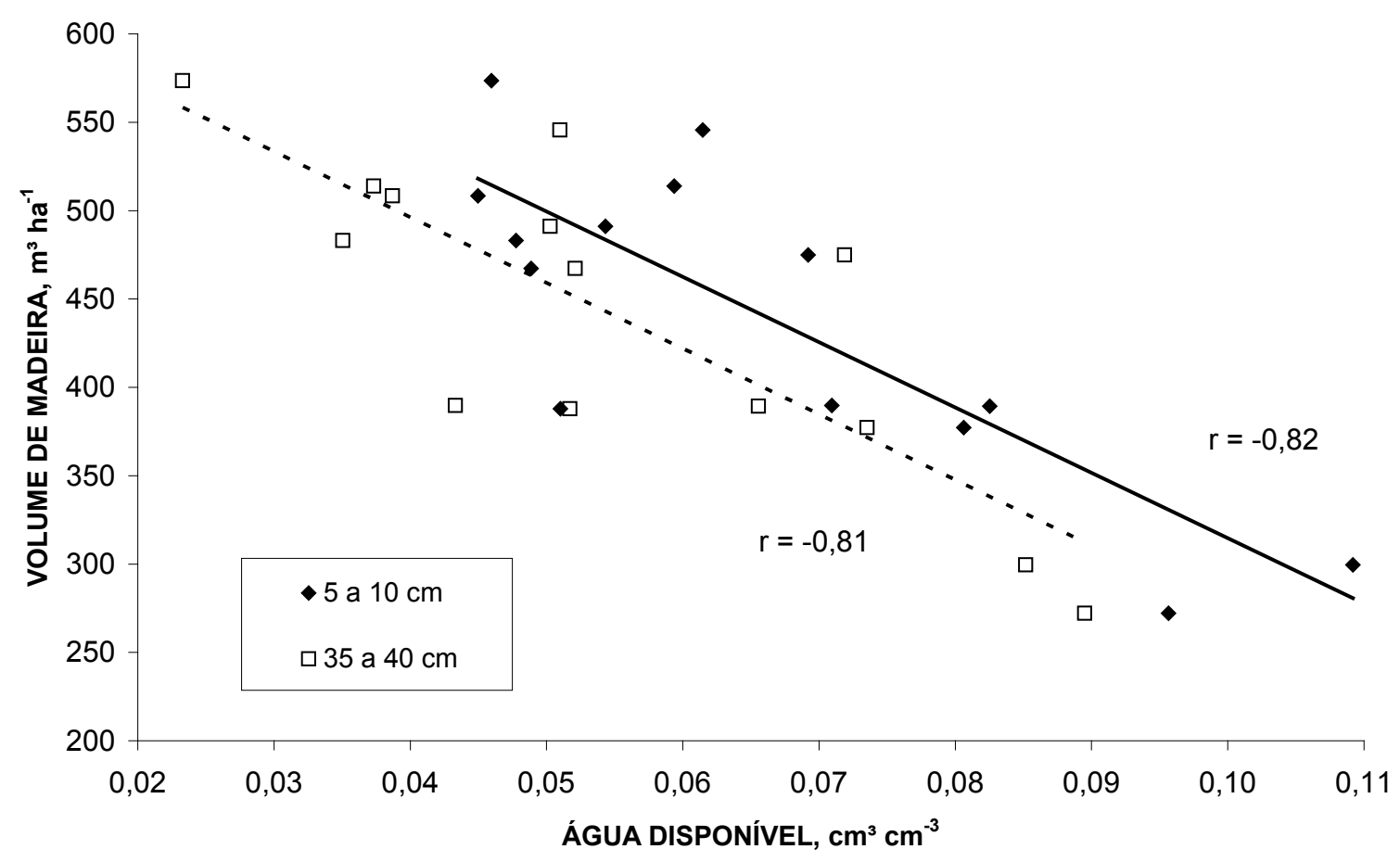

Figura 6. Correlação linear entre o volume de madeira de Pinus taeda com 13/14 anos de idade e o conteúdo de unidade na capacidade de campo, nas profundidades de $5 \mathrm{~cm}$ a $10 \mathrm{~cm}$ e $35 \mathrm{~cm}$ a $40 \mathrm{~cm}$, Rio Negrinho e Tijucas do Sul, SC, 2006. 
O teor de argila não é o principal responsável pela redução do crescimento do $P$. taeda. Isso ocorre pois, embora as correlações não sejam muito expressivas (r menor que -0,59), houve correlação linear negativa entre o teor de argila e o conteúdo de água disponível (Figura 7). Com a fração silte, o conteúdo de água disponível correlacionou-se positivamente, embora o coeficiente de determinação baixo destas correlações não permite afirmar a importância delas. $\mathrm{O}$ alto teor de matéria orgânica (Tabela 1) nos solos menos produtivos (parcelas 5b, 9 e 2) pode ter contribuído para o maior teor de água disponível. Estes mesmos solos contrastam com a maioria dos solos dos sítios de 13/14 anos. A maioria parece ter perdido o horizonte A original por efeito de erosão ou mesmo raspagem da camada superficial dos solos na derrubada e no enleiramento efetuado por lâmina da vegetação original. A formação de uma camada orgânica nestes solos é ainda muito incipiente e, em média, não ultrapassa $2 \mathrm{~cm}$ de espessura. A maior mineralização da matéria orgânica em condições de menor umidade, menor quantidade e $\mathrm{pH}$ mais elevado pode ter contribuído para um maior crescimento das árvores (Lea \& Ballarrd, 1982).

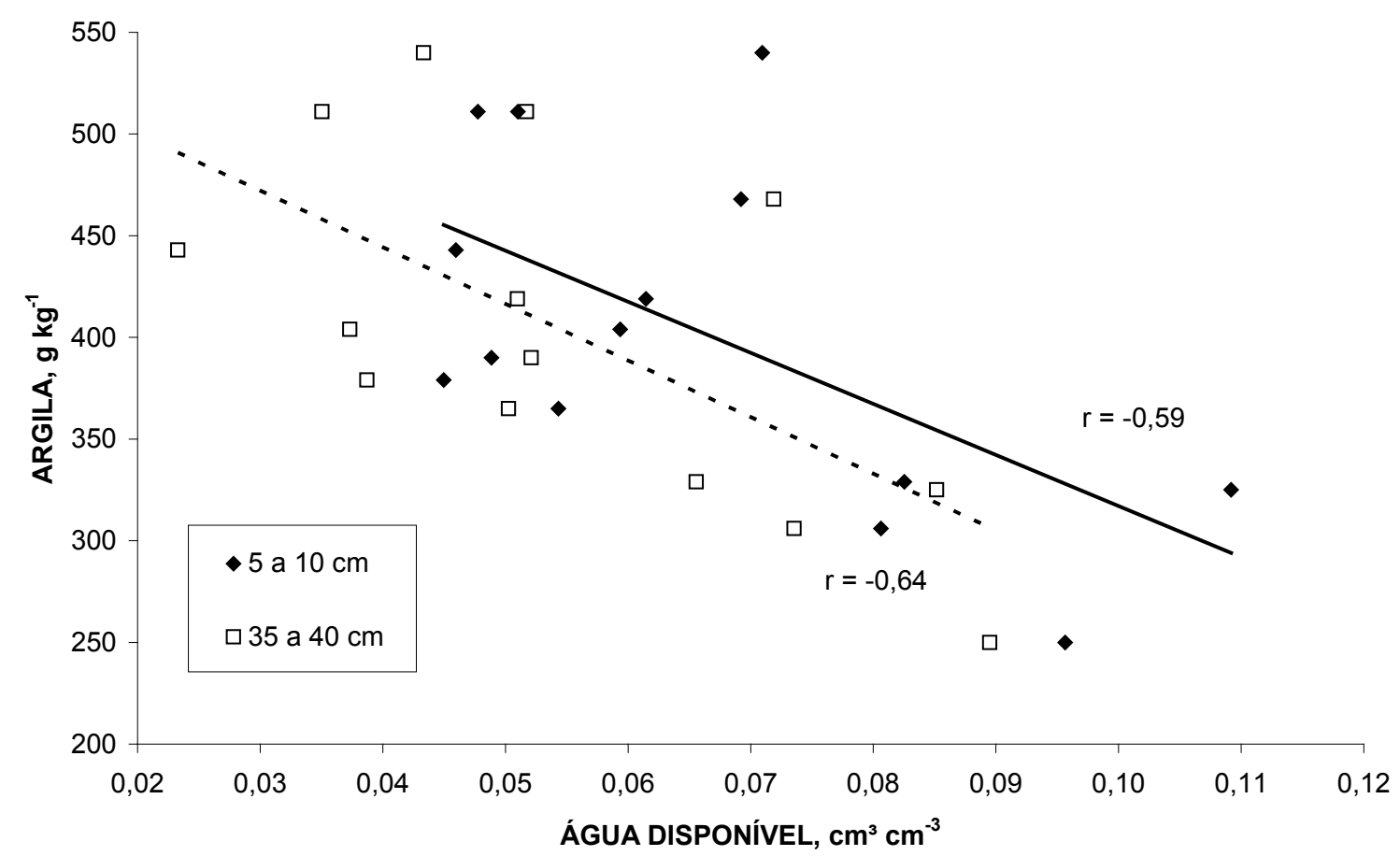

Figura 7. Correlação linear entre o conteúdo de água disponível e o teor de argila no solo das parcelas com Pinus taeda com 13/14 anos de idade, nas profundidades de 0 a $5 \mathrm{~cm}$ e $35 \mathrm{~cm}$ a $40 \mathrm{~cm}$, Rio Negrinho e Tijucas do Sul, SC, 2006.

\section{Conclusões}

$\mathrm{O}$ maior incremento médio anual de árvores de $P$. taeda ocorre nos solos dos sítios estudados com maior macroporosidade e porosidade de aeração nas camadas de $5 \mathrm{~cm}$ a $10 \mathrm{~cm}$ e $35 \mathrm{~cm}$ a $40 \mathrm{~cm}$;

Solos com maior disponibilidade de água reduzem o incremento médio anual das árvores de $P$. taeda, em condições climáticas de ausência de déficit hídrico;

A textura do solo com teores muito semelhantes de areia e argila, com dominância da fração argila, proporciona o maior desenvolvimento do P. taeda.

\section{Referências}

BELLOTE, A. F. J. Influência dos nutrientes minerais e dos atributos do solo sobre a produtividade, a estrutura anatômica e a densidade da madeira produzida pelo Pinus taeda. 2005. 94 p. Relatório final (Pós-doutorado) - Escola Superior de Agricultura "Luiz de Queiroz", Universidade de São Paulo, Piracicaba.

BOGNOLA, I. A. Unidades de manejo para Pinus taeda L. no Planalto Norte Catarinense, com base em características do meio físico. Curitiba, 2007. 160 p. Tese (Doutorado em Ciências Florestais) - Setor de Ciências Agrárias, Universidade Federal do Paraná, Curitiba. 
CORREIA, J. R., COSTA, L. M. da; NEVES, J. C. L.; CRUZ, C. D. Estudo do relacionamento entre características físicas e químicas do solo e a produtividade do gênero Pinus. Revista Árvore, Viçosa, v. 22, n. 2, p. 161-169. 1996.

DEDECEK, R. A.; FIER, I. S. N.; SPELTZ, R.; LIMA, L. C. S. Influência do sítio no desenvolvimento do Pinus taeda aos 22 anos: 1. características físico-hídricas e químicas do solo. Revista Floresta, Curitiba, v. 38, n. 3, p. 507-516, jul./set. 2008.

QUINTEROS DOLDAN, M. E. Desenvolvimento da altura dominante de Pinus taeda L. como resposta aos estímulos dos fatores do meio, na região de Ponta Grossa. Revista Floresta, Curitiba, v. 20, n. 1/2, p. 54-55. 1990.

CLAESSEN, M. E. C. (Org.). Manual de métodos de análise de solo. 2. ed. rev. atual. Rio de Janeiro: EMBRAPA-CNPS, 1997. 212 p. (EMBRAPA-CNPS. Documentos, 1).

SANTOS, H. G. dos;JACOMINE, P. K. T.; ANJOS, L. H. C. dos;OLIVEIRA, V. A. de;OLIVEIRA, J. B. de; COELHO, M. R.; LUMBRERAS, J. F.; CUNHA, T. J. F. (Ed.).Sistema brasileiro de classificação de solos.2. ed. Rio de Janeiro: Embrapa Solos, 2006. 306 p. il. Inclui apêndices.

HILLEL, D. Fundamentals of soil physics. New York: Academic Press, 1980. 413 p.

LACEY, S. T. Soil deformation and erosion forestry. Sydney, Forest Commission of New South Wales, 1993. 62p.

LEA, R.; BALLARD, R. Predicting loblolly pine growth response from $\mathrm{N}$ fertilizer, using soil-N availability indices. Soil Science Society of America Journal, v. 46, n.6, p. 1096-1099. 1982.
MORRIS, L. A.; LUDOVICI, K. H.; TORREANO, S. J.; CARTER, E. A., LINCOLN, M. C.; WILL, R. E. An approach for using general soil physical condition-root growth relationships to predict seeding growth response to site preparation tillage in loblolly pine plantations. Forest Ecology and Management, v. 227, n. 1-2, p. 169-177. 2006.

OLARIETA, J. R.; BESGA, G.; RODRIGUES-OCHOA,R.; AIZPURUA, A.; USÓN, A. Land evaluation for forestry: a study of the land requirements for growing Pinus radiata D. Don in the Basque Country, northern Spain. Soil Use and Management, London, v.22, n.3, p. 238-244. 2006.

REISSMANN, C. B.; WISNEWSKI, C. Aspectos nutricionais de plantios de Pinus. In: GONÇALVES, J. L. M.; BENEDETTI, V. Nutrição e fertilização florestal. Piracicaba: IPEF, 2000. p. 135-166.

RIGATTO, P. A.; DEDECEK, R. A.; MATOS, J. L. M. de. Influência dos atributos do solo sobre a qualidade da madeira de Pinus taeda para produção de celulose Kraft. Revista Árvore, Viçosa, v. 28, n. 2, p. 267-273. 2004.

SNOWDON, P.; BENSON, M. L. Effects of combinations of irrigation and fertilization on the growth and above-ground biomass production of Pinus radiata. Forest Ecology and Management, Amsterdam, v. 52, n. 1/4, p. 87-116, 1992.

WOLKOWSKI, R. P. Relationship between wheel-traffic-induced soil compaction, nutrient availability, and crop growth: a review. Journal of Production in Agriculture, v. 3, n. 4, p. 460-469. 1990. 
